\title{
Editorial \\ Tumour necrosis factor blockade and the risk of osteoporosis: back to the future
}

\author{
Philip Sambrook
}

Kolling Institute, University of Sydney, Sydney, Australia

Corresponding author: Philip Sambrook, sambrook@med.usyd.edu.au

Published: 30 August 2007

Arthritis Research \& Therapy 2007, 9:107 (doi:10.1186/ar2277)

This article is online at http://arthritis-research.com/content/9/4/107

(c) 2007 BioMed Central Ltd

See related research article by Marotte et al., http://arthritis-research.com/content/9/3/R61

\begin{abstract}
Osteoporosis is a common clinical problem, especially in patients with rheumatoid arthritis (RA). A reduction in bone mineral density (BMD) of the axial and appendicular skeleton ranging from $7 \%$ to $15 \%$ has been reported in RA in studies employing a variety of densitometric techniques. Reports consistent with a beneficial effect of tumour necrosis factor blockade on BMD have begun to emerge in recent years, and in Arthritis Research and Therapy, a case control study reports that patients treated with infliximab for RA had preservation of BMD in the lumbar spine and femoral neck compared to those treated with methotrexate.
\end{abstract}

Generalised osteoporosis is just one of three bony manifestations of rheumatoid arthritis (RA), which also include erosions and localised juxta-articular bone loss of affected joints. Although a number of causes for this generalised osteoporosis have been proposed [1,2], increasing evidence suggests a common mechanism for all three bone manifestations. Control of inflammation appears to be the most important strategy for prevention of bone loss in RA [3].

The discovery of the receptor activator of nuclear factor $\kappa B$ (RANK) ligand (RANKL) pathway, a transmembrane protein belonging to the tumour necrosis factor (TNF) superfamily, and its inhibition by osteoprotogerin (OPG) has had important implications for bone physiology as well as inflammation research. RANK and its decoy receptor OPG are key regulators of osteoclastic bone resorption in vitro and in vivo $[4,5]$. Osteoblasts express RANKL constitutively on their cell surface. This interacts with its cognate receptor RANK, which is expressed on osteoclast precursors and promotes osteoclast differentiation. Interaction of RANKL with RANK on mature osteoclasts results in their activation and prolonged survival. OPG is secreted primarily by osteoblasts and stromal cells. OPG blocks the interaction of
RANKL with RANK and thus acts as a physiological regulator of bone turnover. These observations suggest that TNF blockade may have a beneficial effect on bone generally, not just on erosions in RA.

In the previous issue of Arthritis Research and Therapy, Marotte and colleagues [6] reported a case control study in 99 patients with RA treated with infliximab. After 12 months, patients receiving infliximab had preservation of bone mineral density (BMD) in the lumbar spine and femoral neck whereas bone loss amounting to $3.9 \%$ and $2.5 \%$ was observed at the same sites, respectively, in the control group treated with methotrexate alone. Changes in biochemical markers of bone turnover from baseline or between the groups were not statistically different. However, the trends in both serum osteocalcin (a formation marker) and serum carboxy-terminal telopeptide of type I collagen (CTX; a resorption marker) suggest that a greater decrease in remodelling activity occurred with infliximab. Of particular interest, the benefit on BMD with infliximab treatment appeared to occur independently of the clinical response in terms of effect on RA activity. Reports consistent with effects of TNF blockade on BMD have begun to emerge in recent years [7-9].

Earlier smaller studies also suggested a beneficial effect of TNF blockade on osteoporosis in RA. Lange and colleagues [7] studied 26 patients with RA treated with infliximab and observed an increase in spine and femoral neck BMD of $2.7 \%$ and $13 \%$, respectively. Serum osteocalcin levels rose whilst a resorption marker (serum crosslaps) fell, but there was no control group. Vis and colleagues [8] also reported stable spine and hip BMD as opposed to an expected decline in 102 RA patients treated with infliximab. Serum CTX levels decreased significantly with infliximab therapy.

$\mathrm{BMD}=$ bone mineral density; CTX = carboxy-terminal telopeptide of type I collagen; OPG = osteoprotogerin; RA = rheumatoid arthritis; RANK = receptor activator of nuclear factor $\mathrm{KB} ; \mathrm{RANKL}=\mathrm{RANK}$ ligand; TNF = tumour necrosis factor. 
Seriolo and colleagues [9] studied 30 RA patients treated with TNF blockers, 11 of whom were treated with etanercept and 10 with infliximab. BMD trends favoured TNF blockade but were small and non-significant. Serum osteocalcin rose and the resorption marker urinary deoxypyrdinoline decreased. Most of these reports have been with infliximab. It is unclear whether a similar trend occurs with other TNF blockers such as etanercept.

A few very early studies have also examined the effect of disease modifying drugs on bone loss in RA using older densitometric techniques like metacarpal morphometry. In a study of 70 patients, Schorn and Mowat [10] reported metacarpal cortical width improved with D-penicillamine after one year. In a subsequent study of 113 patients, Schorn [11] reported $\mathrm{D}$-penicillamine but not oral gold reversed bone loss over 12 months. In a study of 81 patients over 18 months, Kalla and colleagues [12] reported significant effects on metacarpal cortical width with sulphasalazine, antimalarials and injectable gold. Of interest, the manual technique of metacarpal morphometry employed in these three old studies is identical with that measured by modern day automated radiogrammetry. Moreoever, automated radiogrammetry using hand $X$-rays shows a strong correlation with BMD assessed by dual energy X-ray absorptiometry [13].

In summary, studies like that by Marotte and colleagues [6] suggest TNF blockade may have a role in prevention of generalised osteoporosis in both rheumatic diseases and postmenopausal osteoporosis. However, properly controlled trials are needed to fully evaluate the effect of TNF blockers in this regard. An interesting observation here is that the availability of automated radiogrammetry means that the effect of TNF blockers on BMD could be easily assessed. Modern clinical trials with TNF blockers in RA have included hand X-rays to assess efficacy. Application of such automated radiogrammetry to the existing clinical trial data (such as these hand $\mathrm{X}$-rays) offers an opportunity to examine the effects of TNF blockade on bone loss and hence osteoporosis. It would also be an example of how older methodology can still provide insights into modern aspects of pathogenesis and treatment - hence the title 'back to the future'.

\section{Competing interests}

The author declares that they have no competing interests.

\section{References}

1. Sambrook PN, Eisman JA, Champion GD, Pocock NA, Eberl S, Yeates MG: Determinants of axial bone loss in rheumatoid arthritis. Arthritis Rheum 1987, 30:721-728.

2. Goldring SR, Gravallese EM: Mechanisms of bone loss in inflammatory arthritis: diagnosis and therapeutic implications. Arthritis Res 2000, 2:33-37.

3. Sambrook PN: The skeleton in rheumatoid arthritis: common mechanisms for bone erosion and osteoporosis? J Rheumatol 2000, 27:2541-2542.

4. Eghbali-Fatourechi G, Khosla S, Sanyal A, Boyle WJ, Lacey DL, Riggs BL: Role of RANK ligand in mediating increased bone resorption in early postmenopausal women. J Clin Invest 2003, 111:1221-1230.
5. Boyle WJ, Scott Simonet W, Lacey DL: Osteoclast differentiation and activation. Nature 2003, 423:337-342.

6. Marotte H, Pallot-Prades B, Grange L, Gaudin P, Alexandre C, Miossec P: A one year case control study in rheumatoid arthritis patients indicates a prevention of bone mineral density loss in both responders and non responders to infliximab. Arthritis Res Ther 2007, 9:R61.

7. Lange U, Teichmann J, Muller-Ladner U, Strunk J: Increase in bone mineral density of patients with rheumatoid arthritis treated with anti-TNF alpha antibody: a prospective open label pilot study. Rheumatology 2005, 44:1546-1548.

8. Vis $M$, Havaardsholm EA, Haugeberg G, Uhlig $T$, Voskuyl AE, van de Stadt RJ, Dijkmans BA, Woolf AD, Kvien TK, Lems WF: Evaluation of bone mineral density, bone metabolism, osteoprotegerin and receptor activator of the NFKB ligand serum levels during treatment with infliximab in patients with rheumatoid arthritis. Ann Rheum Dis 2006, 65:1495-1499.

9. Seriolo B, Paolino S, Sulli A, Ferretti V, Cutolo M: Bone metabolism changes during anti-TNF-alpha therapy in patients with active rheumatoid arthritis. Ann NY Acad Sci 2006, 1069:420427.

10. Schorn D, Mowat AG: Penicillamine in rheumatoid arthritis: Wound healing, skin thickness and osteoporosis. Rheumatol Rehab 1977, 16:223-229.

11. Schorn D: Osteoporosis of the rheumatoid hand - the effects of treatment with D-penicillamine and oral gold salts. South Afr Med J 1983, 63:121-123.

12. Kalla AA, Meyers OL, Chalton D, Heath S, Brown GMM, Smith PR, Burger MC: Increased metacarpal bone mass following 18 months of slow acting antirheumatic drugs for rheumatoid arthritis. Br J Rheumatol 1991, 30:91-100.

13. Black DM, Palermo L, Sorensen T, Jorgensen JT, Lewis C, Tylavsky F, Wallace R, Harris E, Cummings SR: A normative reference database study for Pronosco X-posure System. J Clin Densitomet 2001, 4:5-12. 